\title{
Abstract \\ Knowledge regarding subfertility among patients who are attending to general surgical and subfertility clinics at the Teaching Hospital Peradeniya.
}

Pethiyagoda $\mathrm{A}^{1^{*}}$, Bandara $\mathrm{D}^{1}$, Dissanayake $\mathrm{M}^{1}$, Wijesuriya $\mathrm{N}^{1}$, Rajapaksha $\mathrm{T}^{1}$, Theswa $\mathrm{E}^{1}$, Pethiyagoda $\mathrm{K}^{1}$

${ }^{1}$ Department of Surgery, Faculty of Medicine, University of Peradeniya

\begin{abstract}
Background

Subfertility is a common medical condition which can lead to many social and psychological problems. Good knowledge regarding subfertility may help to decrease the incidence of infertility by allowing couples to avoid certain risk factors and it will facilitate the management. The aim of our study was to assess knowledge regarding subfertility among Sri Lankans.

\section{Method}

A cross-sectional study was conducted with a total of 426 subjects including 158 fertile participants, 138 unmarried participants from general surgical clinics and 130 subfertile patients from the subfertility clinic at the teaching hospital Peradeniya. Study was conducted using a self administered questionnaire during May, June and July 2015.

\section{Results}

Generally a poor level of knowledge $(44.71 \%)$ was reported by participants. Knowledge was significantly higher in subfertile group (48.93\%) compared to fertile $(42.32 \%, \mathrm{P}=0.006)$ and unmarried $(43.47 \%, \mathrm{P}=0.035)$ groups. Only $29.81 \%$ of total population knows when to seek medical advices for subfertility, with no significant difference between groups (fertile-30.4\%, subfertile- $28.5 \%$, unmarried-30.4\%). Though $69.73 \%$ of total population $(60.1 \%$ of fertile, $89.2 \%$ of subfertile, $60.9 \%$ of unmarried) correctly recommended a Gynaecologist for first consultation, only $8.23 \%$ of total ( $7 \%$ of fertile, $4.6 \%$ of subfertile, $13 \%$ of unmarried) correctly selected Andrologist for male fertility problems.

\section{Conclusions}

These findings suggest poor knowledge regarding subfertility, particularly regarding male subfertility which is far less than knowledge regarding female subfertility. In general, subfertile patients have a significantly higher level of knowledge than fertile and unmarried patients, but regarding some specific points all three groups have a low level of knowledge.
\end{abstract}

Key words: Knowledge; Subfertility; Male Fertility

Copyright: $\odot 2015$ Pethiyagoda A et al. This is an open access article distributed under the Creative Commons Attribution License, which permits unrestricted use, distribution, and reproduction in any medium, provided the original work is properly cited.

\footnotetext{
*Correspondence : pethiya@yahoo.com
}

Cite this abstract as: Pethiyagoda A, Bandara D, Dissanayake M, Wijesuriya N, Rajapaksha T, Theswa E, Pethiyagoda K. Knowledge regarding subfertility among patients who are attending to general surgical and subfertility clinics at the Teaching Hospital Peradeniya. Anuradhapura Medical Journal 2015;9 (2Supp):S28.

DOI: http://dx.doi.org/10.4038/amj.v9i2Supp.7577 
Submit your next Manuscript to Anuradhapura

Submit your manuscript at http://amj.sljol.info/ 